Revista Geográfica Digital. IGUNNE. Facultad de Humanidades. UNNE. Año 9. № 17. Enero - Junio 2012.

ISSN 1668-5180 Resistencia, Chaco

\title{
GEOGRAFÍA MÉDICA Y DE LA SALUD: CONCEPTOS, PARADIGMAS Y VISIONES EN EL CONTEXTO DEL CAMBIO CLIMÁTICO
}

\author{
Dr. José Seguinot Barbosa, \\ Departamento de Salud Ambiental \\ Recinto de Ciencias Médicas \\ Universidad de Puerto Rico \\ jose.seguinot@upr.edu
}

\section{RESUMEN}

La geografía médica es la rama de la geografía que se ocupa del estudio de los efectos del medio ambiente en la salud de las personas y de la distribución geográfica de las enfermedades incluyendo también el estudio de los factores ambientales que influyen en su propagación. El objeto de estudio de la geografía médica es el ser humano, su comunidad y sociedad, el estudio de las regiones de salud y de las relaciones mutuas entre el individuo, el medio natural, los vectores que transmiten las enfermedades, los factores de riesgo o propensión al deterioro de la salud de una población y las condiciones de infraestructura y atención en los servicios de salud de una comunidad. Los conceptos asociados a los campos de la epidemiologia (ciencia que estudia las enfermedades) y la geografía médica son relativamente poco conocidos y difundidos en las ciencias humanas y naturales. Se habla en muchos contextos de diferentes conceptos tales como la incidencia, la prevalencia, natalidad, mortalidad, morbilidad, entre otros. El calentamiento global y el cambio climático afectan la salud de la población mundial mediante un aumento de las tasas de mortalidad y de la morbilidad. También incrementa la vulnerabilidad de nuestra población a los desastres como huracanes e inundaciones. Los grupos de edad de alto riesgo, como los viejos y niños no están preparados para resistir temperatura mucho más altas. Se puede asociar una mayor frecuencia de enfermedades respiratorias y de cáncer en la piel a condiciones de cambio global. Los científicos sostienen que el cambio climático produce temperaturas y lluvias extremas, con olas de calor, inundaciones y sequías. Estos cambios extremos producen, a su vez, efectos directos sobre la mortalidad y la morbilidad. Tenemos que establecer políticas y leyes cónsonas con el cambio climático para prevenir sus impactos en la salud y la morbilidad de la población. En síntesis el cambio climático ya está con nosotros y debemos adaptarnos a esta realidad.

PALABRAS CLAVES: geografía médica, cambio climático, prevalencia, incidencia, natalidad, mortalidad.

\section{MEDICAL AND HEALTH GEOGRAPHY: CONCEPTS, PARADIGMS AND VISIONS IN THE CONTEXT OF CLIMATE CHANGE}

\begin{abstract}
Medical geography is the branch of geography which deals with the study of the effects of the environment on the health of people and the geographical distribution of diseases including also

Publicado en formato digital: Dr. José Seguinot Barbosa. GEOGRAFíA MÉDICA Y DE LA SALUD: CONCEPTOS, PARADIGMAS Y VISIONES EN EL CONTEXTO DEL CAMBIO CLIMÁTICO. Revista Geográfica Digital. IGUNNE. Facultad de Humanidades. UNNE. Año 9. No 17. Enero - Junio 2012. ISSN 1668-5180 Resistencia, Chaco. En: http://hum.unne.edu.ar/revistas/geoweb/default.htm
\end{abstract}


the study of the environmental factors that influence in their spread. The object of study of medical geography is the human being, his community and society, the study of health and regions of mutual relations between the individual, the natural environment, vectors transmitting diseases, factors of risk or propensity to the deterioration of the health of a population and the conditions of health infrastructure and care in a community health services. The concepts associated with the fields of Epidemiology (science that studies diseases) and medical geography are relatively little known and disseminated in the humanities and natural sciences. It is spoken in many contexts of different concepts such as incidence, prevalence, birth, mortality, morbidity, among others. Global warming and climate change affect the health of the world's population through an increase in the rates of mortality and morbidity. It also increases the vulnerability of our population to disasters such as hurricanes and floods. Age of high-risk groups, such as the elderly and children are not prepared to withstand much higher temperature. We can associate a greater frequency of respiratory diseases and cancer in the skin to conditions of global change. The scientists argue that climate change produces temperatures and extreme rainfall, with heat waves, droughts and floods. These extreme changes, in turn, have a direct effect on mortality and morbidity. We need to establish policies and laws consistent with climate change to prevent their impacts on health and morbidity of the population. To sum up climate change is already with us and we must adapt to this reality.

KEY WORD: Medical geography, climate change, prevalence, incidence, natality and mortality. 


\section{GEOGRAFÍA MÉDICA Y DE LA SALUD: CONCEPTOS, PARADIGMAS Y VISIONES EN EL CONTEXTO DEL CAMBIO CLIMÁTICO}

\section{INTRODUCCIÓN}

La geografía médica es la rama de la geografía que se ocupa del estudio de los efectos del medio ambiente en la salud de las personas y de la distribución geográfica de las enfermedades incluyendo también el estudio de los factores ambientales que influyen en su propagación. Es parte de la geografía humana que a su vez estudia las sociedades humanas desde una óptica espacial, la relación entre estas sociedades y el medio físico en el que habitan y los paisajes culturales que éstas construyen. La geografía médica parte de la premisa de que el ser humano siempre forma parte de agrupaciones sociales amplias. Estas sociedades crean un entorno social y físico mediante procesos de transformación de sus propias estructuras sociales y de la superficie terrestre en la que se asientan. Estas transformaciones se deben a procesos económicos, políticos, culturales y demográficos que culminan influenciando la condición de salud de una población dada.

El objeto de estudio de la geografía médica es el ser humano, su comunidad y sociedad, el estudio de las regiones de salud y de las relaciones mutuas entre el individuo, el medio natural, los vectores que transmiten las enfermedades, los factores de riesgo o propensión al deterioro de la salud de una población y las condiciones de infraestructura y atención en los servicios de salud de una comunidad. El desarrollo progresivo del conocimiento en la geografía médica obligó a su sucesiva integración con otras ramas de la geografía consideradas como ciencias o ramas relativamente autónomas. Todo ello vino a sustituir el concepto original de la geografía médica por una integración de una serie de conocimientos sistemáticos estudiados con más detalle por ciencias como: la Geografía de la población, que estudia los patrones de distribución de los seres humanos, la Geografía económica, que estudia los patrones y procesos económicos y su distribución en el tiempo y el espacio terrestre, la Geografía cultural, que investiga las relaciones mutuas entre los seres humanos y el paisaje, la Geografía urbana, que es la ciencia que estudia las aglomeraciones humanas representadas por las ciudades y la Geografía rural que estudia el mundo rural y las estructuras de los sistemas agrarios.

Es común encontrar a la geografía médica asociada con otras disciplinas afines en el estudio de la salud humana y de los sistemas de salud. Por ejemplo, el concepto de Geografía de la Salud es el más ampliamente difundido entre los geógrafos. El término de la salud en geografía aparece por primera vez documentada en el Siglo XVIII por el médico alemán Leonhard Finke en su obra "Geographie" en la que se plasma la relación que puede tener el espacio con la salud, para describir las enfermedades mismas y la solución a éstas. La geografía dedica sus esfuerzos a analizar las características de localización y distribución de las manifestaciones de los grupos humanos, de los elementos naturales, sus diferencias locales, su dinámica espacio temporal y sus interrelaciones en la superficie terrestre o espacio. Los estudios desarrollados por la geografía deben responder a algunas de las preguntas que se asocian con las formas de vida y la estructura

Publicado en formato digital: Dr. José Seguinot Barbosa. GEOGRAFíA MÉDICA Y DE LA SALUD: CONCEPTOS, PARADIGMAS Y VISIONES EN EL CONTEXTO DEL CAMBIO CLIMÁTICO. Revista Geográfica Digital. IGUNNE. Facultad de Humanidades. UNNE. Año 9. № 17. Enero - Junio 2012. ISSN 1668-5180 Resistencia, Chaco. En: http://hum.unne.edu.ar/revistas/geoweb/default.htm 
territorial en la que se encuentran, principalmente ¿dónde? y ¿cuándo? Es decir, distingue aquellas variables que se encuentran ligadas íntima e inexorablemente al lugar en un tiempo determinado en que transcurren los hechos como la salud. El lugar es conocido en la geografía profesional como espacio geográfico, que no es otra cosa que el escenario biótico, abiótico y social en que se desenvuelven las actividades humanas. En principio, el espacio es el objeto de estudio de la geografía, debido a que es allí precisamente, donde se llevan a cabo los numerosos eventos naturales y sociales, y en esta actividad los mapas tienen un papel de suma importancia. (http://sincronia.cucsh.udg.mx/gonzalez07.htm

Otro campo ampliamente relacionado con la geografía médica y que está muy de moda en estos tiempos es la aplicación de los Sistemas de Información Geográfica en la Salud (SIG en Salud). Según Luisa Iñiguez (2003) en la segunda mitad de la década del noventa, se asiste a un renovado interés por el lugar, componente tradicional de la epidemiología, y especialmente por los mapas. En el contexto latinoamericano, diferentes grupos e instituciones privilegian la localización, la distribución espacial y territorial, tanto en los análisis de enfermedades de alta prioridad, emergentes, o reemergentes, como en los procesos de descentralización de la administración sectorial, del sector salud. Paralelamente, el desarrollo de las tecnologías de procesamiento y análisis automatizado de bases de datos geo-referenciados, impulsa el uso de la cartografía automatizada y de los sistemas de información geográfica en salud. La conciencia acerca de la drástica ampliación de las desigualdades e inequidades sociales y sanitarias de las poblaciones latinoamericanas, y la paulatina incorporación de enfoques emanados de la medicina social y de la salud colectiva, completan el contexto favorable para el protagonismo de la localización, la distribución, la diferenciación espacial y territorial, orientado por nuevos objetivos prioritarios: la estratificación la tipificación o la focalización espacial de problemas y necesidades en salud”. 
Revista Geográfica Digital. IGUNNE. Facultad de Humanidades. UNNE. Año 9. № 17. Enero - Junio 2012.

\section{Disciplinas GEO-Médlicas}

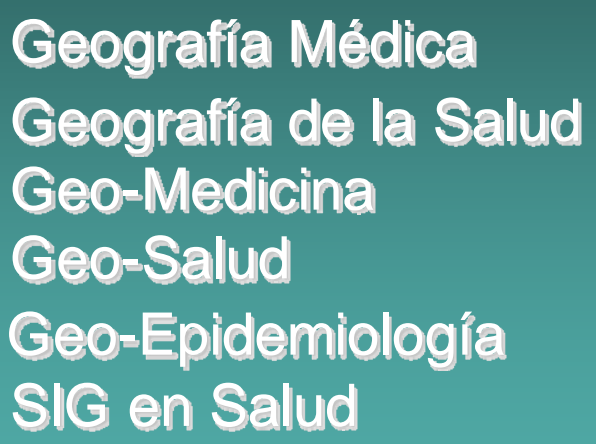

La Geo-Medicina o geología médica también es un campo ampliamente en crecimiento. La génesis de la evolución de la Geología Médica puede remontarse a la actuación del factor ambiental como uno de los factores causales que afectan la salud. Los impactos de los materiales geológicos sobre la salud han sido reconocidos por la humanidad desde hace miles de años. Esta disciplina se desarrolló como respuesta a la comprensión de la degradación ambiental producida como consecuencia de los impactos antropogénicos generados por la tecnología industrial. La publicación del libro La Primavera Silenciosa (Silent Spring) en el año 1962, ha sido la expresión más prematura de este resultado que a su vez ha llegado a ser definido por el marco de causaefecto entre la salud y el ambiente.

Un campo de estudio estrechamente vinculado a la geografía médica es la Salud Ambiental. La "salud ambiental" tiene numerosas denominaciones, pero en general todas tienden a enfatizar la protección ambiental, la preservación, la restauración ambiental y en general todas las actuaciones orientadas a la disminución de los efectos nocivos que el ambiente produce en la salud, salvaguardando el bienestar general de las personas ahora y en el futuro. La Organización Mundial de la Salud (OMS) propone la siguiente definición: "La salud ambiental comprende aquellos aspectos de la salud humana, incluida la calidad de vida, que son determinados por factores ambientales físicos, químicos, biológicos, sociales y psicosociales. También se refiere a la teoría y práctica de evaluación, corrección, control y prevención de los factores ambientales que pueden afectar de forma adversa la salud de la presente y futuras generaciones". Los factores determinantes de la salud ambiental, son aquellos que pertenecen a la realidad física y ambiental sobre los que se debe actuar a fin de satisfacer necesidades de los seres humanos. De este modo, se entiende que existen aspectos de la salud y las enfermedades humanas que pueden 
Revista Geográfica Digital. IGUNNE. Facultad de Humanidades. UNNE. Año 9. № 17. Enero - Junio 2012. ISSN 1668-5180 Resistencia, Chaco

ser determinados por los factores ambientales. (http://html.rincondelvago.com/saludambiental.html).

\section{HISTORIA}

Es difícil precisar con certeza cuando se utilizó por vez primera el concepto de geografía médica. La gran mayoría de los autores le atribuyen a Hipócrates (450 AC) la creación del concepto científico y de original este enfoque del pensamiento geográfico. Sin embargo, la construcción científica y social del concepto de geografía médica y de sus escuelas y ciencias auxiliares asociadas (geografía de la salud, epidemiología, salud ambiental, etc.) fue muy posterior, es decir mucho más reciente en nuestra historia humana.

Si retrocedemos al desarrollo del conocimiento y pensamiento occidental es decir al periodo de los griegos vamos a encontrar en figuras como Herodoto (485 AC), Eratóstenes (194 AC) y Estrabón (64 AC) variadas referencia a la relación entre el ser humano con su mundo natural. Fue Hipócrates (500 AC) el que en su obra sobre la geografía médica primero presentó el concepto de la influencia ambiental en el carácter humano. En la edad media y el renacimiento se destacaron figuras como Ibn Batuta (1368), Al Idrisi y el navegante italiano Marco Polo (1325). Ellos fueron observadores de los cambios que acontecían en la naturaleza causados por la influencia humana. En el renacimiento la Geografía General que escribió Varenio (1622) sirvió de base para comprender la estrecha relación entre los países existentes, sus habitantes y la relación con el clima, el paisaje y la flora y fauna e incluso la salud. Con los trabajos de Charles Darwin (1860) y el posterior desarrollo del pensamiento ecológico, después de la publicación de su obra titulada: El Origen de las Especies, el análisis ecológico y humano tomó un gran impulso (Jensen, 1980).

Varios naturalistas como Alexander Von Humboldt (1859) y Car Ritter (1859) contribuyeron ampliamente a la integración del medio natural con el medio social y cultural. Friedrich Ratzel (1882) continúo con la tradición socio ambiental al sostener que el ser humano vive bajo leyes naturales. Esta tradición pasó a los Estados Unidos por medio de su discípula Ellen Churchill Semple (1932). En su trabajo ella enfatizó siempre en la influencia que tenía el medio ambiente en la cultura y la sociedad humana, incluyendo su salud. La tradición francesa legó a través de Vidal de La Blanche (1920) el concepto de ecología humana. Harlan Barrows (1922) introdujo esta tradición en los Estados Unidos. El enfoque fundamental de este paradigma era estudiar las asociaciones humanas con su medio ambiente. Max Sorre fue uno de los discípulos de Vidal de la Blache que más contribuyó al desarrollo de la geografía humana en Francia. En El hombre en la Tierra se presentan algunos enunciados que sirven para definir a la geografía humana francesa desde una óptica ecológica y paisajística. A partir de entonces se desarrolló toda una línea de pensamiento asociadas a la ecología humana, la sociedad y la salud. Entre ellos se incluyen la ecología de poblaciones, la ecología sistémica, los ecosistemas y las muchas ramificaciones de la ecología que conocemos en la actualidad, incluyendo la geografía de la salud.

Publicado en formato digital: Dr. José Seguinot Barbosa. GEOGRAFíA MÉDICA Y DE LA SALUD: CONCEPTOS, PARADIGMAS Y VISIONES EN EL CONTEXTO DEL CAMBIO CLIMÁTICO. Revista Geográfica Digital. IGUNNE. Facultad de Humanidades. UNNE. Año 9. No 17. Enero - Junio 2012. ISSN 1668-5180 Resistencia, Chaco. En: http://hum.unne.edu.ar/revistas/geoweb/default.htm 
En Puerto Rico desde hace mucho tiempo se vienen haciendo contribuciones a la geografía médica. En las últimas cuatro décadas en el campo de la geografía médica hay dos geógrafos puertorriqueños que han realizado sus proyectos de tesis doctoral sobre Puerto Rico. La profesora Sonia Arbona llevó a cabo un estudio sobre los elementos ambientales que determinaron la distribución de algunos elementos patógenos en Puerto Rico. El profesor Víctor Santiago llevó a cabo un estudio similar, pero considerando los aspectos socioeconómicos de la población. En el año 2001 se llevó a cabo en el Instituto de Estudios Hemisféricos en Ciencias Medicas un estudio sobre la distribución geográfica del SIDA en Puerto Rico. Este trabajo en conjunto con varios otros relacionados al campo de la salud han sido publicados en el texto titulado Geonatura (Seguinot, 2001).

La difusión de la geografía médica por parte de nuestro grupo de trabajo en el Recinto de Ciencias Medicas ha sido muy amplia. En estos últimos años nos hemos integrado a la colaboración con colegas de la Universidad de Lujan en Argentina y su grupo de trabajo en la geografía de la salud. Por lo que hemos publicado varios trabajos vinculados al tema en su Revista de Geografía de la Salud (www.geografiadelasalud.com.ar/bol_3.pdf). También hemos colaborado con la Dra. Luisa Iñiguez de la Universidad de la Habana en un estudio comparativo entre Cuba y Puerto Rico para VIH, Tuberculosis y otras enfermedades transmisibles. También publicamos un artículo sobre La Geografía Médica en Puerto Rico en el texto sobre métodos cuantitativos aplicados a la salud compilado por el Dr. Gustavo Buzai (2006).

Según esta breve historia el desarrollo de la geografía médica ha estado supeditado a otros temas vinculados al desarrollo de la geografía y la ecología como disciplinas. Su lugar como escuela de análisis científico alcanzó su máximo esplendor con el desarrollo de las políticas de salud y ambiente, tanto nacionales, locales, regionales e internacionales que iniciaron su amplio desarrollo en la década de 1970, alcanzando su máxima expresión en la primera década de este siglo 21. 


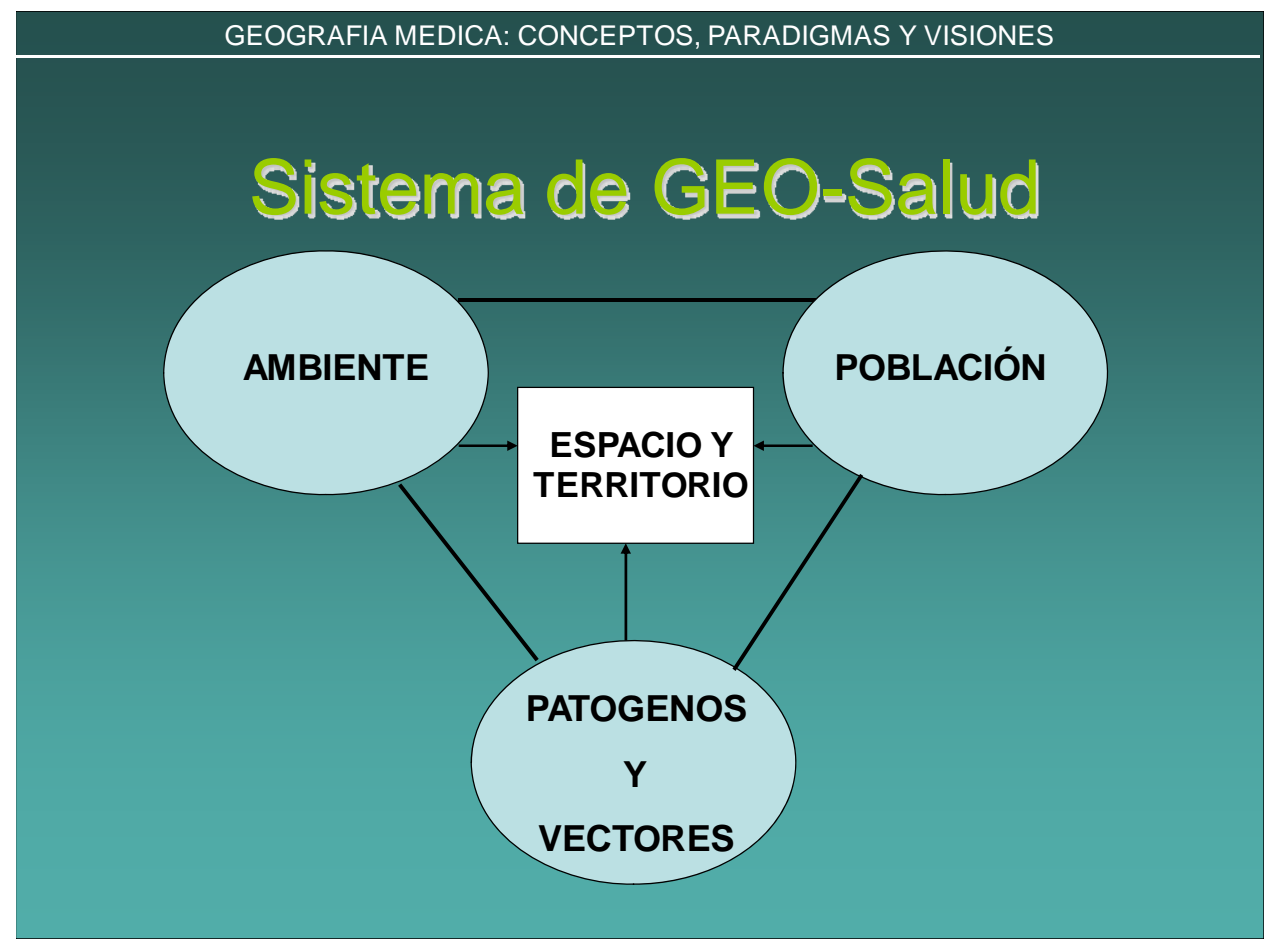

\section{CONCEPTOS FUNDAMENTALES}

Los conceptos asociados a los campos de la epidemiologia (ciencia que estudia las enfermedades) y la geografía médica son relativamente poco conocidos y difundidos en las ciencias humanas y naturales. Se habla en muchos contextos de diferentes conceptos tales como la incidencia, la prevalencia, natalidad, mortalidad, morbilidad, entre otros. Lo interesante es que los diferentes tipos de conceptos se interrelacionan entre sí para formar en muchas ocasiones epistemologías nuevas que reflejan nuevas realidades sociales y de salud. Eso precisamente es lo que ocurre con los conceptos de justicia ambiental, pobreza, y marginación. La situación se complica aún más cuando asociamos diferentes conceptos y categorías ambientales a los conceptos de salud. Términos como degradación, preservación, conservación y contaminación nos describen una acción o un estado actual de la naturaleza que está asociada a un nivel de impacto humano sobre ese ambiente.

Un concepto fundamental básico es la enfermedad que tal y como se observa en el cuadro siguiente constituye una alteración más o menos grave del cuerpo humano, animal o vegetal. Las enfermedades se consideran congénitas cuando se nace con ellas, adquiridas cuando se cogen después de haber nacido, crónicas cuando se extienden por un periodo largo de tiempo, degenerativas cuando afectan seriamente a algún órgano humano, e infecciosas cuando se adquieren por la presencia de algún microorganismo. La frecuencia de enfermedades en una población determina su morbilidad, mientras que la prevalencia constituye el número total de personas afectadas y la incidencia representa el número de casos nuevos. Una enfermedad se considera endémica si tiene una duración relativamente corta en tiempo y espacio, cuando tiene 
una duración muy limitada en tiempo y espacio se considera una epidemia y cuando es ilimitada en el tiempo, aunque limitada en el espacio se considera una pandemia.
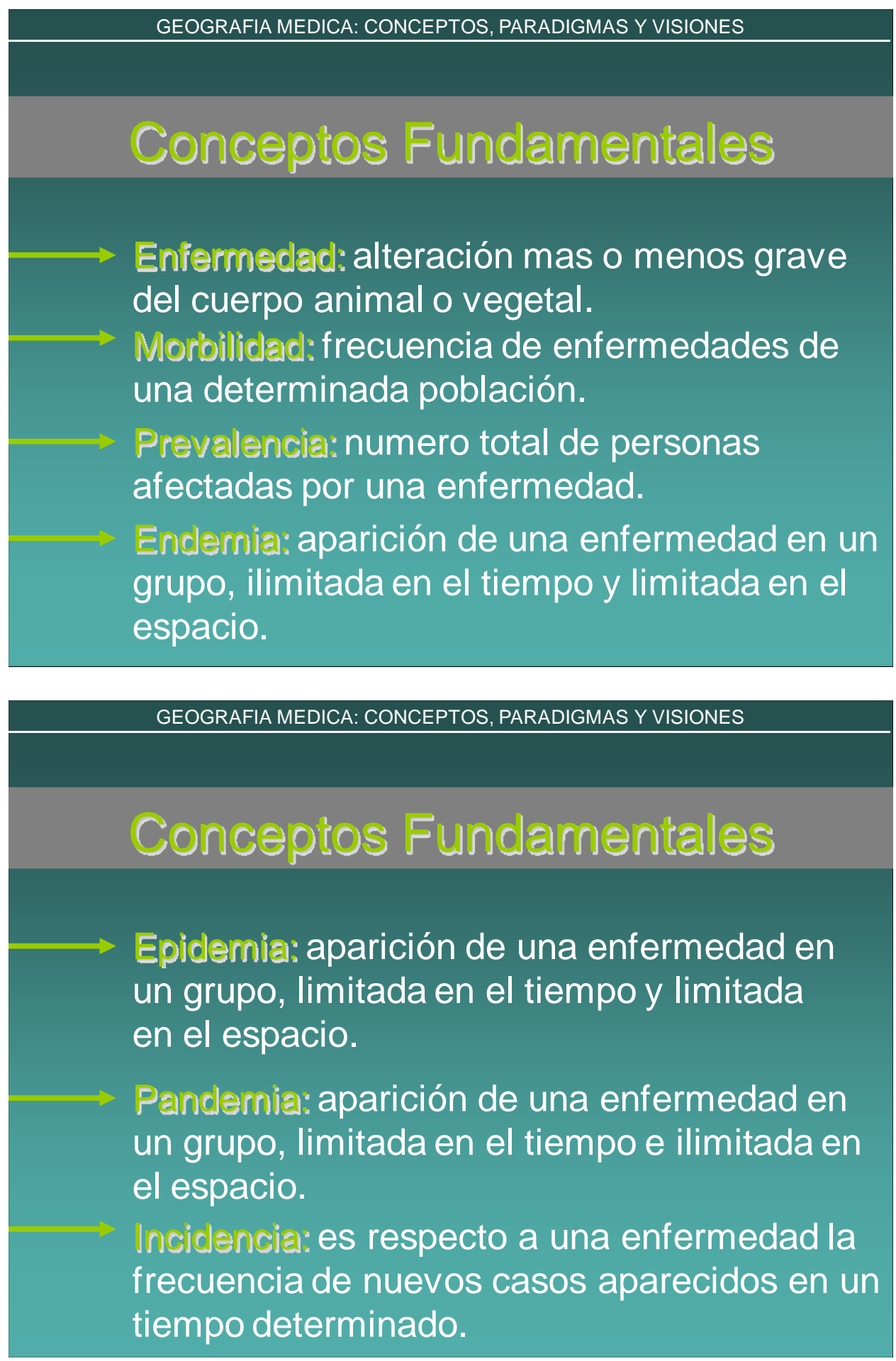

Publicado en formato digital: Dr. José Seguinot Barbosa. GEOGRAFÍA MÉDICA Y DE LA SALUD: CONCEPTOS, PARADIGMAS Y VISIONES EN EL CONTEXTO DEL CAMBIO CLIMÁTICO. Revista Geográfica Digital. IGUNNE. Facultad de Humanidades. UNNE. Año 9. No 17. Enero - Junio 2012. ISSN 1668-5180 Resistencia, Chaco. En: http://hum.unne.edu.ar/revistas/geoweb/default.htm 
Revista Geográfica Digital. IGUNNE. Facultad de Humanidades. UNNE. Año 9. № 17. Enero - Junio 2012. ISSN 1668-5180 Resistencia, Chaco

\section{GEOGRAFIA MEDICA: CONCEPTOS, PARADIGMAS Y VISIONES}

\section{Concepios Fundamentales}

Mortallidad: número proporcional de

defunciones de una población en un periodo

de tiempo.

Patógeno: elementos y medio donde se desarrollan las enfermedades.

Vector: ser vivo o enfermo que sirve como eslabón en la transmisión de una enfermedad.

Los organismos que transmiten una enfermedad como lo puede ser un mosquito, una rata o el mismo ser humano se consideran como el vector de la enfermedad que transmiten. El elemento patógeno constituye el medio mediante el cual se desarrollan y transmite la enfermedad. Así el agua, el aire, los alimentos y la sangre pueden constituir elementos patógenos en un momento dado. Los factores de riesgos conforman los hábitos, costumbres y condiciones genéticas que predisponen al ser humano a ser vulnerable a una enfermedad. Ya conocemos que fumar, consumir alcohol y usar drogas predispone el cuerpo a sufrir enfermedades asociadas a problemas con el sistema inmunológico y respiratorio. Los factores de riesgo también incluyen la edad, sexo y condiciones económicas de una población. Por eso los niños y los viejos son generalmente más vulnerables a sufrir enfermedades que otros grupos humanos. 
Revista Geográfica Digital. IGUNNE. Facultad de Humanidades. UNNE. Año 9. № 17. Enero - Junio 2012. ISSN 1668-5180 Resistencia, Chaco

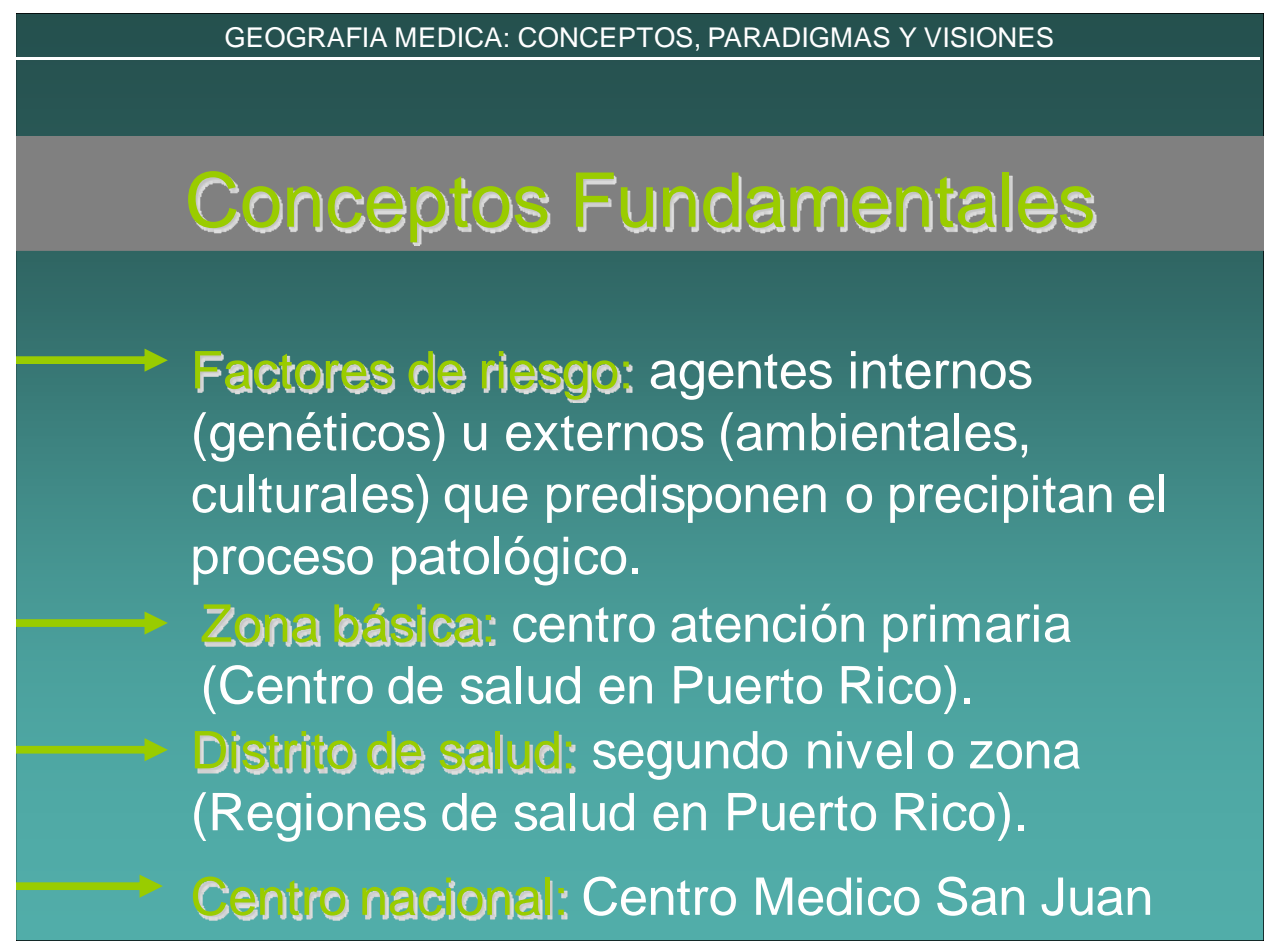

\section{INDICADORES DE SALUD}

La mejor forma de conocer la situación de salud de un individuo o grupo humano es aplicando los indicadores básicos de salud a esta población. La disponibilidad de información respaldada con datos válidos y confiables es una condición necesaria para el análisis y evaluación objetiva de la situación sanitaria, la toma de decisiones basada en evidencia y la programación en salud. Las medidas de morbilidad, discapacidad y de determinantes no biológicos de la salud, como el acceso a servicios, la calidad de la atención, las condiciones de vida y los factores ambientales son de necesidad creciente para analizar con objetividad la situación de salud de grupos poblacionales y para documentar la capacidad de las personas de funcionar física, emocional y socialmente. Para facilitar la cuantificación y evaluación de las diferentes dimensiones del estado de salud de una población es necesario utilizar los indicadores de salud.

Un indicador de salud es "una noción de la vigilancia en salud pública que define una medida de la salud (la ocurrencia de una enfermedad o de otro evento relacionado con la salud) o de un factor asociado con la salud (el estado de salud u otro factor de riesgo) en una población especificada." En términos generales, los indicadores de salud representan medidas que capturan información relevante sobre distintos atributos y dimensiones del estado de salud y del desempeño del sistema de salud y que, vistos en conjunto, intentan reflejar la situación sanitaria de una población.

Publicado en formato digital: Dr. José Seguinot Barbosa. GEOGRAFíA MÉDICA Y DE LA SALUD: CONCEPTOS, PARADIGMAS Y VISIONES EN EL CONTEXTO DEL CAMBIO CLIMÁTICO. Revista Geográfica Digital. IGUNNE. Facultad de Humanidades. UNNE. Año 9. № 17. Enero - Junio 2012. ISSN 1668-5180 Resistencia, Chaco. En: http://hum.unne.edu.ar/revistas/geoweb/default.htm 
La construcción de un indicador es un proceso de complejidad variable, desde el recuento directo (casos nuevos de malaria en la semana) hasta el cálculo de proporciones, razones, tasas o índices más sofisticados (esperanza de vida al nacer). La calidad de un indicador depende fuertemente de la calidad de los componentes (frecuencia de casos, tamaño de población en riesgo, etc.) utilizados en su construcción, así como de la calidad de los sistemas de información, recolección y registro de tales datos. Específicamente, la calidad y utilidad de un indicador está primordialmente definida por su validez (si efectivamente mide lo que intenta medir) $\mathrm{y}$ confiabilidad (si su medición repetida en condiciones similares reproduce los mismos resultados). Los atributos de calidad de un indicador de salud son su especificidad (que mida solamente el fenómeno que se quiere medir), sensibilidad (que pueda medir los cambios en el fenómeno que se quiere medir), mensurabilidad (que sea basado en datos disponibles o fáciles de conseguir), relevancia (que sea capaz de dar respuestas claras a los asuntos más importantes de las políticas de salud) y su costo-efectividad (que los resultados justifiquen la inversión en tiempo y otros recursos). Los indicadores deben ser fácilmente utilizados e interpretables por los analistas y comprensibles por los usuarios de la información, como los gerentes y los que toman las decisiones.

Los indicadores deben ser generados y manejados dentro de un sistema de información dinámico. Los indicadores de salud constituyen una herramienta fundamental para la toma de decisiones en todos los niveles de gestión. De manera general, un conjunto básico de indicadores de salud como el que forma parte de la Iniciativa Regional de la Organización Panamericana de la Salud (OPS) de Datos Básicos en Salud y Perfiles del País tiene como propósito generar evidencia sobre el estado y tendencias de la situación de salud en la población. Esto incluye la documentación de desigualdades en salud, la evidencia que debe servir de base empírica para la determinación de grupos humanos con mayores necesidades en salud, la estratificación del riesgo epidemiológico y la identificación de áreas críticas como insumo para el establecimiento de políticas y prioridades en salud. La disponibilidad de un conjunto básico de indicadores provee la materia prima para los análisis de salud. Simultáneamente, puede facilitar el monitoreo de objetivos y metas en salud, estimular el fortalecimiento de las capacidades analíticas en los equipos de salud y servir como plataforma para promover el desarrollo de sistemas de información en salud intercomunicados. En este contexto, los indicadores de salud válidos y confiables son herramientas básicas que requiere la epidemiología para la gestión en salud. http://www.paho.org/spanish/sha/be_v22n4-indicadores.htm.

\footnotetext{
Publicado en formato digital: Dr. José Seguinot Barbosa. GEOGRAFíA MÉDICA Y DE LA SALUD: CONCEPTOS, PARADIGMAS Y VISIONES EN EL CONTEXTO DEL CAMBIO CLIMÁTICO. Revista Geográfica Digital. IGUNNE. Facultad de Humanidades. UNNE. Año 9. No 17. Enero - Junio 2012. ISSN 1668-5180 Resistencia, Chaco. En: http://hum.unne.edu.ar/revistas/geoweb/default.htm
} 
Revista Geográfica Digital. IGUNNE. Facultad de Humanidades. UNNE. Año 9. № 17. Enero - Junio 2012. ISSN 1668-5180 Resistencia, Chaco

GEOGRAFIA MEDICA: CONCEPTOS, PARADIGMAS Y VISIONES

\section{Indicadores de salud}

Mortallidad: fallecidos/población X 1.000

Morbillidalad: Enfermas/población X 1.000

Riesgo relativyo: P.exp./P.n.exp. X 1.000

Letallidad: fallecidos $x$ enf./ afectados X 1.000

Canas: \#camas/población X 10.000

Farnasias: \#F./población x 10.000

GEOGRAFIA MEDICA: CONCEPTOS, PARADIGMAS Y VISIONES

\section{Indicadores de salud ambiental}

- Hacinamiento

- Acceso agua potable

- Servicios sanitario

- Recogido de basura

- Ratas, mosquitos

- Hambre y nutrición

- Tabaco y drogas

- Actividad física
- Calidad de agua, aire

- Calidad de suelo

- Calidad de vida

- Niveles sostenibilidad

- Tensión social

- Transporte y ruidos

- Recreación

- Crecimiento cultural 


\section{POBLACIONES VULNERABLES}

Las poblaciones vulnerables son aquellas que por factores tanto físicos como sociales dependen de otras personas para llevar una vida plena y saludable. Ellas incluyen los niños y las personas de edad avanzada. En el caso de los niños, necesitan personas que los cuiden y los alimenten para poder desarrollarse y crecer. Asimismo, las personas de edad avanzada, muchas veces requieren de cuidados especiales debido a condiciones de salud o impedimentos físicos que limitan su movilidad.

Desde los años 60 Puerto Rico experimenta cambios en su estructura de edad, característica que según los últimos censos hace considerar a la población de Puerto Rico, como una de edad avanzada. Según el Censo de Población y Vivienda de 1990, la población de 60 años o más ascendía a 465,736 y representó 13.2\% de la población total. Entre 1980 y 1990, este grupo poblacional aumentó en 108,232. En términos porcentuales, el aumento fue de 30.3\%. Las últimas cifras disponibles corresponden al Censo Poblacional y Vivienda del año 2000. Según esta fuente, la población de 60 años o más totalizó 585,701 lo que representa un 15.4\% de la población total (Oficina de la Procuradora de Personas de Edad Avanzada). Dada esta situación se hace imprescindible tomar en cuenta esta población como una extremadamente vulnerable a cualquier desastre natural. Lo cual es de suma importancia si se toma en cuenta que el cambio climático trae consigo un aumento en la cantidad de ese tipo de desastres.

Esta vulnerabilidad se debe a su mayor fragilidad, indefensión, exclusión y dificultades en la integración social en una etapa del ciclo vital donde ésta se transforma en una necesidad aún más básica y cuando se hace todavía más difícil satisfacerla. Según La Carta de Derechos de las Persona de Edad Avanzada estas personas tienen derecho a vivir en un ambiente de tranquilidad, respeto y dignidad que satisfaga las necesidades básicas de vivienda, de alimentación, de salud y económicas, con atención a sus condiciones físicas, mentales, sociales, espirituales y emocionales (Ley Núm. 121 de 12 de Julio de 1986, p. 399, según enmendada). Por ejemplo el hecho de que una persona de edad avanzada viva en una zona inundable violenta su derecho vivir en un ambiente de tranquilidad y satisfacer sus necesidades básicas de vivienda. Esto podría causar también problemas de ansiedad e inseguridad entre los miembros de esta población ya que es mucho más difícil para una persona mayor reaccionar con rapidez a este tipo de emergencia. Existen factores sociales como la marginación y el abandono de parte de los hijos y el resto de la población que podrían agravar esta situación.

La UNISEF define como "niño" o "niña" a toda persona menor de 18 años, a menos que las leyes de un determinado país reconozcan antes la mayoría de edad. Los niños constituyen otra población altamente vulnerable a cualquier tipo de desastre natural. Luego de una inundación los niños están más expuestos a enfermedades, heridas e incluso a perder la vida. También pueden verse forzados a abandonar sus hogares, quedar huérfanos o separase de sus familias. Un ejemplo reciente de esto fue el terremoto de Haití, ocurrido en 2010, donde cientos de niños quedaron huérfanos y desamparados.

Publicado en formato digital: Dr. José Seguinot Barbosa. GEOGRAFíA MÉDICA Y DE LA SALUD: CONCEPTOS, PARADIGMAS Y VISIONES EN EL CONTEXTO DEL CAMBIO CLIMÁTICO. Revista Geográfica Digital. IGUNNE. Facultad de Humanidades. UNNE. Año 9. № 17. Enero - Junio 2012. ISSN 1668-5180 Resistencia, Chaco. En: http://hum.unne.edu.ar/revistas/geoweb/default.htm 
La Convención sobre los Derechos del Niño, adoptada por la Asamblea General de la ONU en 1989 y ratificada hasta la fecha por 193 países, junto con la Declaración "Un Mundo Apropiado para los Niños” (WFFC por sus siglas en inglés), protegen y preservan el derecho de cada niño a un medio ambiente seguro y saludable en el cual desarrollarse y crecer. De la misma manera, el Estado Libre Asociado de Puerto Rico reconoce en La Carta de Derecho del Niño el vivir en un ambiente adecuado en el hogar de sus padres y en familias donde se satisfagan sus necesidades físicas y disfrutar el cuidado, afecto y protección que garantice su pleno desarrollo físico, mental, espiritual, social y moral (Ley 338, 1998 según enmendada).

Según la Organización de las Naciones Unidas (ONU) un desastre es todo evento concentrado en tiempo y espacio en el cual una comunidad sufre daños severos y tales pérdidas afectan a sus miembros y a sus pertenencias físicas de forma tal que se resienta la estructura social y las principales funciones de la sociedad. El riesgo de ocurrencia de un desastre depende de la amenaza y la vulnerabilidad. La primera es un factor externo a una comunidad expuesta representado por la potencial ocurrencia de un fenómeno desencadenante (Fochiatti, 2005). La vulnerabilidad que se define como la disposición interna a ser afectado por una amenaza. Según Fochiatti existen diferentes tipos de vulnerabilidad. La vulnerabilidad natural se refiere a que todos los seres humanos necesitan ciertas condiciones ambientales y sociales para poder desarrollarse. Los niños debido a su inmadurez física, cognitiva y fisiológica son a menudo más vulnerables a los desastres. Una lluvia intensa en Puerto Rico se puede convertir en un aumento de la incidencia del Dengue, enfermedad que en el caso de los niños o los envejecientes puede ser grave. La vulnerabilidad física define claramente la situación de las comunidades que residen en la zonas inundables ya que se refiere a la localización de la población en zonas de riesgo físico, condición provocada por la pobreza y/o la falta de oportunidad para una ubicación de menor riesgo (Fochiatti, 2005).

La vulnerabilidad económica que explica la relación entre ingresos y el impacto de los fenómenos físicos externos, se ve reflejada en la población de edad avanzada.

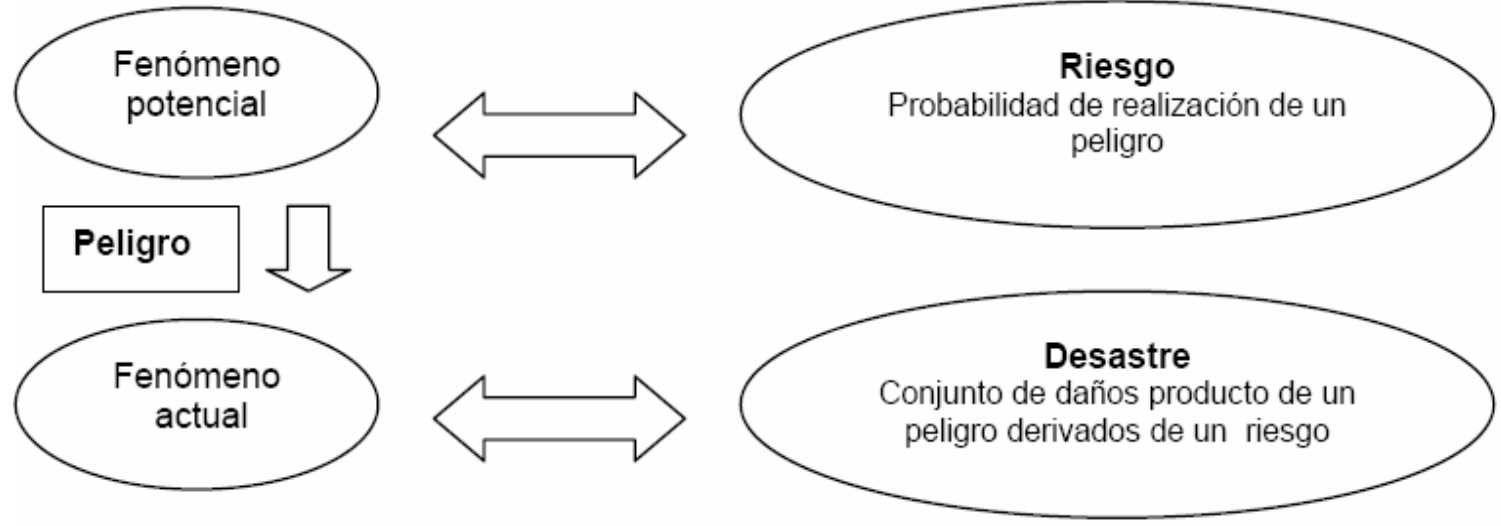

Foschiatti (2005) Vulnerabilidad Global y Pobreza, Universidad Nacional Nordeste, Argentina.

En el año 2000 la población de 60 años y más con algún grado de dependencia en Puerto Rico llegaba a las 182.819 personas (hombres y mujeres), sobre un total de 589.446 (es decir, un 31\%

Publicado en formato digital: Dr. José Seguinot Barbosa. GEOGRAFÍA MÉDICA Y DE LA SALUD: CONCEPTOS, PARADIGMAS Y VISIONES EN EL CONTEXTO DEL CAMBIO CLIMÁTICO. Revista Geográfica Digital. IGUNNE. Facultad de Humanidades. UNNE. Año 9. No 17. Enero - Junio 2012. ISSN 1668-5180 Resistencia, Chaco. En: http://hum.unne.edu.ar/revistas/geoweb/default.htm 
de personas mayores dependientes, si considerar los casos perdidos que son el $0.3 \%$ de los casos) (Monteverde et al. 2008). A esto se le suma la crisis económica que hace cada vez más difícil el que las familias se hagan cargo de ellos. Al comparar con otros países en América latina, Puerto Rico es el país con costos individuales más altos tanto en dólares, en términos de paridad de poder de compra y en relación al ingreso individual y familiar.

Los niños desde pequeños son capaces de reconocer agentes estresantes en el hogar. Cuando se crían en lugares seguros son capaces de aprender respuestas de afrontamiento adaptativo sanas. Un entorno seguro es necesario para desarrollar un sentido de confianza la falta de este puede ser estresante. La manera en que un desastre o evento natural va a afectar a un niño depende de cómo sus padres manejen la situación. Consecuentemente, es importante que las personas que viven en zonas inundables sepan como orientar a sus hijos de manera que se sientan seguros en especial cuando es un evento recurrente en la vida de los niños.

En síntesis los riesgos ambientales son más peligrosos para los niños que para los adultos. Por una parte, es más fácil que estén expuestos a las amenazas ambientales en comparación con los adultos. Por la otra, debido a que el cuerpo todavía se está desarrollando es posible que la exposición de los niños a los riesgos ambientales tenga mayores consecuencias en comparación con los adultos. Ciertos comportamientos particulares y las diferentes etapas del desarrollo hacen que los niños se lleven a la boca, las manos y diversos objetos; que rueden y gateen por el suelo o el piso; que se suban a lugares peligrosos; que descubran sus alrededores y prueben nuevas aptitudes. Si bien toda estas actividades son normales, suelen colocar a los niños en situaciones peligrosas si viven, juegan, aprenden o trabajan en un ambiente degradado, contaminado o inseguro. Por lo general, los niños viven en ambientes menos seguros y más contaminados o degradados; a la vez sufren de nutrición deficiente y tienen el sistema inmunitario debilitado, lo que no les permite luchar contra la enfermedad y la infección. También es común que los niños pobres entren a formar parte de la fuerza laboral a muy corta edad para sostenerse ellos mismos o a su familia. http://www.paho.org/spanish/ad/sde/sde-children.htm

Desde su inicio, la Organización Panamericana de la Salud (OPS) ha estado trabajando en la salud ambiental de los niños. Por ser la OPS una de las partes interesadas en la salud ambiental de los niños acudió al llamamiento a la acción de la Declaración de 1997 de los Responsables del Medio Ambiente del Grupo de los Ocho sobre la Salud Infantil y el Medio Ambiente. Desde entonces, han emprendido estudios, proyectos, iniciativas, así como un programa regional llamado Ambientes sanos, niños sanos. En todas estas actividades han colaborado con los países miembros y a menudo han recibido apoyo valioso de los Estados Unidos y Canadá a fin de obtener el financiamiento y el apoyo técnico necesarios para llevar adelante esta iniciativa fundamental de esta organización. Su trabajo que ha estado destinado a mejorar los entornos saludables para los niños se basa en varios programas de la organización, como el de Atención Integrada a las Enfermedades Prevalentes de la Infancia, Salud del Niño y Salud del $\underline{\text { Adolescente, }} \underline{\text { la Iniciativa de Escuelas Promotoras de la Salud, y las Iniciativas de Ciudades }}$ Saludables.

\footnotetext{
Publicado en formato digital: Dr. José Seguinot Barbosa. GEOGRAFíA MÉDICA Y DE LA SALUD: CONCEPTOS, PARADIGMAS Y VISIONES EN EL CONTEXTO DEL CAMBIO CLIMÁTICO. Revista Geográfica Digital. IGUNNE. Facultad de Humanidades. UNNE. Año 9. No 17. Enero - Junio 2012. ISSN 1668-5180 Resistencia, Chaco. En: http://hum.unne.edu.ar/revistas/geoweb/default.htm
} 


\section{CAMBIO CLIMÁTICO Y SALUD}

Se define el Cambio Climático (CC) como la modificación en los elementos del clima que ha tenido lugar respecto a su escala regional y global causada por factores naturales y/o humanos. El calentamiento global es el signo más evidente del cambio climático. Ambos afectan la salud de la población mundial mediante un aumento de las tasas de mortalidad y de la morbilidad. También incrementan la vulnerabilidad de nuestra población a los desastres como huracanes e inundaciones. Los grupos de edad de alto riesgo, como los viejos y niños no están preparados para resistir temperatura mucho más altas. Si se suman el calentamiento global y las islas urbanas de calor, las temperaturas podrían ascender hasta 5 grados Celsius por encima de lo normal. En Puerto Rico se están registrando temperaturas altas extremas con mayor frecuencia que nunca antes. San Juan por ejemplo presenta un aumento térmico promedio de cerca de $4^{\circ} \mathrm{F}$ comparado con las temperaturas de los años cuarenta. Igualmente Ponce y Mayagüez suelen registrar temperaturas más altas que en el pasado.

Se puede asociar una mayor frecuencia de enfermedades respiratorias y de cáncer en la piel a condiciones de cambio global. Por ejemplo, el aumento en la prevalencia de asma, cáncer de la piel y de mayor incidencia de dengue en la población de Puerto Rico puede relacionarse a los efectos del cambio climático. La cantidad de ozono presente en nuestra tropósfera combinado con una mayor cantidad de partículas, polvo del Sahara y cenizas del volcán Le Sofriere, en Montserrat, entre otros contaminantes ha incrementado la cantidad de casos por afecciones respiratorias. A largo plazo tratar todos estos casos conlleva un costo y una inversión mayor por parte de los ciudadanos y del gobierno (Tabla 1).

Entre las enfermedades directamente asociadas al cambio climático se incluyen: el dengue, la malaria, el paludismo, la ciguatera, la enfermedad de Lyme, la encefalitis viral, el cólera, la salmonelosis, el E.coli, la meningitis, el asma, la bronquitis, la pulmonía, el cáncer de la piel, las cataratas y la pérdida del sistema inmunológico. La exposición a radiación ultravioleta también afecta seriamente la salud. Actualmente se requieren medidas preventivas como gafas de sol, sombrero y una exposición limitada a un máximo de un par de horas. De tener una exposición mayor nos arriesgamos a incrementar el cáncer de la piel, perder la visión y hasta afectar el sistema inmunológico y nervioso. Los datos de cáncer en la piel para los Estados Unidos demuestran un aumento drástico en las tasas de incidencia luego de los 50 años de edad y un incremento general desde el año 1999.

Los científicos sostienen que el cambio climático produce temperaturas y lluvias extremas, con olas de calor, inundaciones y sequías. Estos cambios extremos producen, a su vez, efectos directos sobre la mortalidad y la morbilidad. Los recursos de agua y de alimentos se vienen reduciendo como consecuencia de la contaminación y del efecto de los eventos catastróficos extremos. Puerto Rico ha sido afectado por la escasez de agua y alimentos básicos durante el paso de eventos extremos como los huracanes Hugo (1989) y George (1998). En este momento somos muy vulnerables a los eventos extremos y nuestra población en riesgo se incrementa cada vez más dado que hemos creado unas condiciones ambientales muy frágiles e inestables. Por

\footnotetext{
Publicado en formato digital: Dr. José Seguinot Barbosa. GEOGRAFÍA MÉDICA Y DE LA SALUD: CONCEPTOS, PARADIGMAS Y VISIONES EN EL CONTEXTO DEL CAMBIO CLIMÁTICO. Revista Geográfica Digital. IGUNNE. Facultad de Humanidades. UNNE. Año 9. NN 17. Enero - Junio 2012. ISSN 1668-5180 Resistencia, Chaco. En: http://hum.unne.edu.ar/revistas/geoweb/default.htm
} 
ejemplo actualmente en Puerto Rico tenemos más zonas inundables que antes porque hemos alterado los drenajes naturales.

Es fundamental hacer conciencia de la magnitud del problema y los efectos del calentamiento global. Igualmente tenemos que educarnos y protegernos, así como disminuir el uso de gases de invernadero. Es necesario promover el uso de energías sostenibles y verdes mientras se protege el medio ambiente. Tenemos que establecer políticas y leyes cónsonas con el cambio climático para prevenir sus impactos en la salud y la morbilidad de la población. En síntesis el cambio climático ya está con nosotros y debemos adaptarnos a esta realidad.

\section{Tabla 1}

\begin{tabular}{|c|c|}
\hline \multicolumn{2}{|c|}{ Impactos del Cambio Climático en la Salud de los Puertorriqueños } \\
\hline Aspectos de salud ambiental & Aspectos sociales \\
\hline 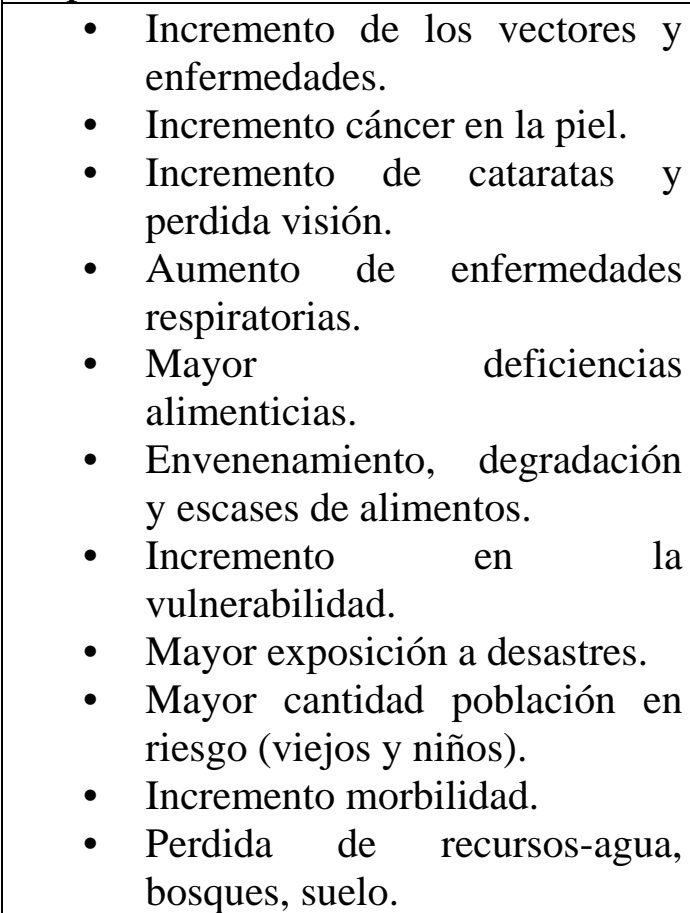 & 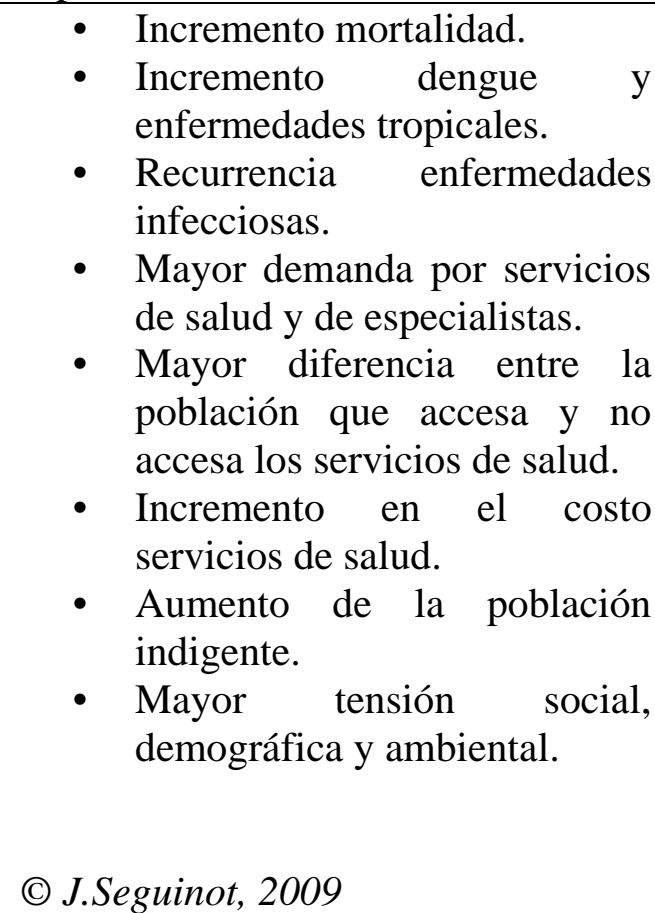 \\
\hline
\end{tabular}

El cáncer de la piel se desarrolla a partir de un crecimiento incontrolado de células de las capas de la piel, que se encuentran en la epidermis. Las células afectadas son células basales, 
escamosas y melanocitos. Los tipos de tumores son nombrados de acuerdo a las células que afectan, por ejemplo, Melanoma. Otros canceres de la piel no melanomas son sarcoma de Kaposi, carcinoma de las células de Merkel y linfoma cutáneo. En ocasiones un cáncer de la piel no tratado se puede diseminar a otros tejidos y órganos del cuerpo del ser humano. Existen diferentes tipos de cáncer de piel, los cuales se llaman; el carcinoma de células basales y el melanoma. De estos dos, el menos común pero más agresivo o peligroso es el melanoma. Estudios han demostrado que este tipo de cáncer es responsable de más de $77 \%$ de las muertes por cáncer de piel (Valentín, 2007).

Cuando hablamos de factores medioambientales que pueden estar relacionados con el desarrollo de una enfermedad nos referimos a todos los factores no genéticos, como la dieta, estilos de vida y agentes infecciosos. Los carcinógenos en el ambiente se pueden encontrar en la contaminación del aire interno y externo, en la radiación solar y los aditivos a la comida (Boffetta, 2003). Los cambios mayores en el medio ambiente global son los cambios climáticos, como lo son el calentamiento global y el deterioro de la capa de ozono. El deterioro de la estratósfera afecta las condiciones de la piel y también puede resultar en enfermedades de los ojos como son las cataratas (Marten, 1998).

En Puerto Rico se han hecho muy pocos estudios para analizar los factores medioambientales y el desarrollo de cáncer de piel. Una de las razones puede ser que esta es una enfermedad con una incidencia baja de $1.67 \%$ para el año 2003 y una tasa de mortalidad menor de $1.0 \%$ para el año 2004 en Puerto Rico (Registro de Cáncer de Puerto Rico, 2009). Aunque, esta no sea una enfermedad considerada como un problema grave de salud pública por su baja mortalidad se debe de investigar a mayor profundidad para entenderla y prevenirla ya que muchas de sus causas son comportamientos modificables. La literatura nos indica constantemente que la mayor causa para esta condición es la luz solar, pero nos debemos de preguntar si existen otros factores de riesgo medioambientales como por ejemplo son: fumar, exponerse al sílice o a las aguas contaminadas.

El Asma es un trastorno inflamatorio de las vías respiratorias que causa episodios de tos, dificultad para respirar y opresión en el pecho (National Asthma Education and Prevention Program Expert Panel Report, 2007). El asma es una enfermedad que afecta las vías respiratorias que van hacia los pulmones. Las vías respiratorias se inflaman y expanden al reaccionar con facilidad a ciertos factores, tales como los virus, el humo o el polen (U.S. Department of Health \& Human Services, 2009). Cuando las vías respiratorias están inflamadas disminuye su diámetro, lo cual causa problemas al respirar. La mayor parte de las personas que sufren de asma tienen ataques separados por períodos asintomáticos. Algunos pacientes tienen dificultad prolongada para respirar con episodios en que este problema se incrementa, mientras que otros pueden presentar tos como el síntoma predominante (U.S. Department of Health \& Human Services, 2009). Los ataques de asma pueden durar de minutos a días y se pueden volver peligrosos si se impide el flujo de aire de manera consistente.

El asma es uno de los problemas de salud pública más serios en Puerto Rico. Según el Departamento de Salud de Puerto Rico las tasas de morbilidad y mortalidad por asma en Puerto Rico son más altas en comparación con los Estados Unidos de América. Durante mucho tiempo

Publicado en formato digital: Dr. José Seguinot Barbosa. GEOGRAFÍA MÉDICA Y DE LA SALUD: CONCEPTOS, PARADIGMAS Y VISIONES EN EL CONTEXTO DEL CAMBIO CLIMÁTICO. Revista Geográfica Digital. IGUNNE. Facultad de Humanidades. UNNE. Año 9. NN 17. Enero - Junio 2012. ISSN 1668-5180 Resistencia, Chaco. En: http://hum.unne.edu.ar/revistas/geoweb/default.htm 
se ha relacionado la condición del asma con varios factores ambientales entre los que se incluye la contaminación atmosférica. El ambiente está directamente relacionado con los patrones del clima, y se ha evidenciado que la contaminación atmosférica también está relacionada con el cambio climático global. Las emisiones a la atmósfera relacionadas con el cambio climático pueden agravar los efectos de la contaminación del aire sobre la salud de los ciudadanos, no solo indirectamente por el impacto en los fenómenos meteorológicos, sino, de manera inmediata, por los efectos directos de los contaminantes en la salud (Ballester, 2005). En síntesis hay suficiente evidencia que demuestra que hay una relación directa entre la contaminación atmosférica, el cambio climático global y efectos a la salud pública dentro de los cuales están incluidos los cambios en los patrones de asma en las poblaciones.

Según el CDC, tanto el dengue como el dengue hemorrágico son causados por uno de cuatro serotipos de virus estrechamente relacionados, pero antigénicamente distintos (DEN-1, DEN-2, DEN-3 y DEN-4), del género Flavivirus. La infección por uno de estos serotipos crea inmunidad de por vida solamente contra ese serotipo, por lo cual las personas que viven en un área donde el dengue es endémico pueden contraer más de una infección por dengue en el transcurso de su vida. La enfermedad es de distribución mundial, sin embargo, es endémico de la región tropical y subtropical entre los 30 grados al norte y los 40 grado al sur del ecuador. Es endémico del sur y este de Asia, el Pacífico, el este y oeste de África, el Caribe y las Américas (Gulati et al., 2007).

En Puerto Rico el dengue es considerado un problema de salud pública debido a que está presente todo el año con fluctuaciones en intensidad. En años donde no ocurren epidemias se reportan entre 3,400 y 7,000 casos. De la misma manera, es importante señalar que es muy difícil eliminar o controlar el vector ya que este se adapta muy bien a cualquier ambiente y se reproduce con mucho éxito en Puerto Rico. En Puerto Rico los casos de dengue son informados mensualmente al Sistema de Vigilancia de Dengue del Center for Disease Control. Según los datos compilados para el año 2003 muestran claramente una tendencia al aumento de casos en los meses de septiembre y octubre que se inicia desde el mes de junio alcanzando su máximo en septiembre. Al buscar las tasas de cada región se puede determinar cuáles son las regiones más afectadas por el dengue.

Tabla 2: Tasas regionales de casos de dengue por cada 100,000 habitantes

\begin{tabular}{l|llllll} 
Región de salud & 2003 & 2004 & 2005 & 2006 & 2007 & 2008 \\
\cline { 1 - 5 } Arecibo & 77.54 & 125.66 & 149.25 & 98.23 & 246.50 & 109.08 \\
\cline { 1 - 4 } & 95.88 & 71.15 & 242.17 & 61.61 & 281.65 & 94.32 \\
\cline { 1 - 5 } Caguas & 44.25 & 57.18 & 81.03 & 76.72 & 191.75 & 69.83 \\
\hline
\end{tabular}


Revista Geográfica Digital. IGUNNE. Facultad de Humanidades. UNNE. Año 9. № 17. Enero - Junio 2012. ISSN 1668-5180 Resistencia, Chaco

\begin{tabular}{|c|c|c|c|c|c|c|}
\hline Fajardo & 116.36 & 80.09 & 64.70 & 105.69 & 449.80 & 103.55 \\
\hline Mayagüez & 77.13 & 62.24 & 134.06 & 53.77 & 291.33 & 46.89 \\
\hline Ponce & 93.16 & 66.65 & 161.63 & 58.28 & 309.61 & 46.74 \\
\hline Metropolitana & 71.87 & 116.89 & 134.59 & 92.68 & 297.28 & 79.86 \\
\hline Total & 576.20 & 579.85 & 967.42 & 546.98 & 2067.91 & 550.26 \\
\hline
\end{tabular}

Fuente: Sistema de Vigilancia de Dengue, CDC, 2009

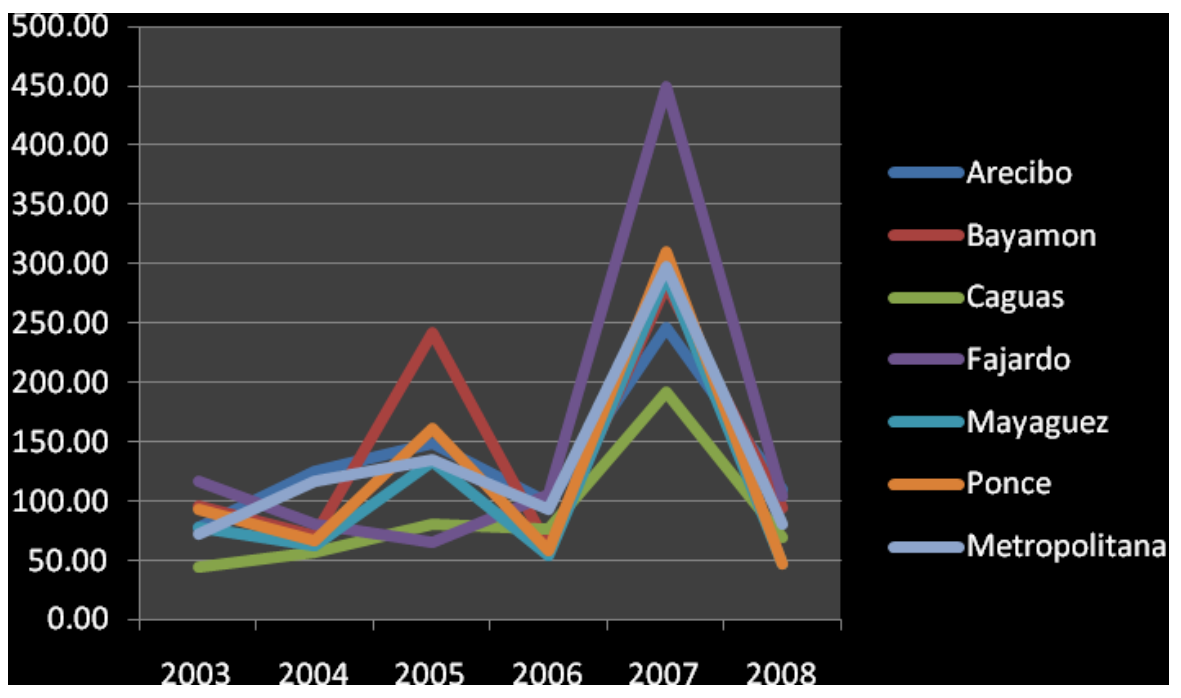

\section{Gráfica 1}

Fuente: Sistema de Vigilancia de Dengue, CDC, 2009.

En la tabla 1 y gráfica 1 se presentan el total de casos de dengue ocurridos desde el año 2003 al 2008 según las tasas crudas existente en ese momento. En la gráfica se puede observar que existen variaciones entre las regiones a través de los años. Sin embargo, igualmente se puede ver como en todas las regiones, excepto Fajardo, se vio un aumento considerable en el número de casos para el año 2005. De la misma manera en el 2007 ocurrió un aumento aun más drástico esta vez reflejado en todas las regiones.

De los análisis realizados podemos concluir que el dengue es el producto directo de condiciones climáticas donde prevalecen una alta humedad y precipitación, asociada también a altas temperaturas. Por eso el dengue siempre ha sido propio de lugares tropicales, aunque con los cambios climáticos hoy día puede presentarse en países tan templados como la Argentina. En Puerto Rico los brotes de dengue han estados asociados con años de calentamiento térmico siendo el 2005 y el 2007 los más representativos. Igualmente son los meses de julio a noviembre donde se presentan la mayor cantidad de casos. Esto coincide con nuestra época lluviosa y con el periodo donde se presentan la mayor cantidad de huracanes. Por el contrario, la presencia de frentes fríos que generalmente coincide con los meses de diciembre a febrero disminuye la 
posibilidad del desarrollo de condiciones que originan el mosquito transmisor del dengue. A base de la realidad que reflejan los datos estudiados para Puerto Rico podemos concluir que el dengue en definitiva es una de las enfermedades más asociadas a los cambios climáticos globales y locales y que Puerto Rico no ha sido la excepción a esta norma.

\section{EXPERIENCIA PROPIA}

¿Qué estudia un geógrafo en el mundo de los médicos y de los salubristas? Es una pregunta un tanto complicada de contestar, a pesar de que todos sabemos que la geografía médica es una de las divisiones más antigua de la geografía. Mi experiencia personal en la salud desde la óptica de un geógrafo que luego estudio derecho, que le interesan los temas ambientales tanto desde la visión técnico científica como social y que aplica los métodos de análisis espacial a través de los Sistemas de Información Geográfica (SIG) ha sido una única. Desde que llegue al recinto de Ciencias Médicas de la Universidad de Puerto Rico hacen exactamente treinta años empecé a interrelacionar con personas de todas las profesiones asociadas a la salud. Allí no solo está el médico, también está el educador en salud, el epidemiólogo, el economista, el administrador, el químico y el radiólogo, entre otros tantos muchos especialista. Es que el campo de la salud es uno verdaderamente interdisciplinario y en ese amplio mundo me introduje como geógrafo.

\section{¿Qué se puede aportar para ganarse un espacio y a su vez conseguir la estima y el respeto de los colegas? La respuesta es simple solo podía aportar lo que sabía hacer y eso era introducir el método espacial y geográfico en las ciencias médicas y de la salud. Así en el año 1990 introduje, en el Recinto de Ciencias Médicas de la Universidad de Puerto Rico, la utilización del SIG en las ciencias de la salud. Ese curso que se inició como una lectura es hoy día uno de los cursos preferidos del estudiantado salubrista. En el año 2000 la Universidad me otorgó una sabática para que escribiera el texto a usarse en el curso, aproveche y me fui a España, a la Universidad de Alcalá de Henares y junto a mis colegas Joaquín Bosque Sendra, Emilio Chuvieco, entre otros produje el texto que se llama: Geonatura: Aplicaciones de los SIG en las Ciencias Ambientales y de la Salud. En el proceso de profesor sin darme cuenta a veces, integré la geografía al derecho y a la salud. Así nació el curso doctoral de Legislación Internacional, Cambios Globales y Salud. También nació el Certificado de Desarrollo Sostenible y el curso de Geología Ambiental y el Seminario de Tópicos Ambientales de Actualidad.}

Con el pasar del tiempo también he trabajados en más de una treintena de proyectos investigativo sobre la salud, en servicios a la comunidad y he administrado varios programas universitarios. Un geógrafo dijo una vez la geografía es lo que los geógrafos hacen y si a lo que he hecho podemos llamarle geografía médica, geografía de la salud o SIG aplicados a la salud es algo que lo dejo a discreción del auditorio.

Publicado en formato digital: Dr. José Seguinot Barbosa. GEOGRAFÍA MÉDICA Y DE LA SALUD: CONCEPTOS, PARADIGMAS Y VISIONES EN EL CONTEXTO DEL CAMBIO CLIMÁTICO. Revista Geográfica Digital. IGUNNE. Facultad de Humanidades. UNNE. Año 9. № 17. Enero - Junio 2012. ISSN 1668-5180 Resistencia, Chaco. En: http://hum.unne.edu.ar/revistas/geoweb/default.htm 
Revista Geográfica Digital. IGUNNE. Facultad de Humanidades. UNNE. Año 9. № 17. Enero - Junio 2012. ISSN 1668-5180 Resistencia, Chaco

Debo confesar que nunca pensé dedicarme a la geografía médica y de la salud. Mi sueño fue siempre estudiar el mar, ese Mar Caribe azul turquesa. Aunque, no he olvidado mi sueño, pues aun trabajo muchos proyectos costeros y del litoral, he incorporado el elemento salud en mi amplio espectro de intereses. La mayor parte de mi vida la paso en el Centro Médico, un conjunto de diez hospitales públicos. Este es un ambiente hospitalario, que aunque universitario, está lleno de contradicciones. Allí llegan los más pobres del país a emergencias médicas. Allí entre heridos, cadáveres, enfermos y llorosos, ponemos en práctica el quehacer geográfico.

\section{REFERENCIAS}

AGUILAR, B. J. (1999): Applications of ecosystem health for the sustainability of managed systems in Costa Rica. Ecosystem Health 5:36-48.

BALLESTER, F. (2005): “Contaminación Atmósferica, cambio climático y salud”, Revista Española de Salud Pública, 79, pp. 159-175.

BARRIGA, G. \& MERCADO, F. (2007): "Microbios africanos de vacaciones en el Caribe: Polvo atmosférico y sus implicaciones para la salud humana”, Revista Mexicana de Patología Clínica, 54, pp. 168-176.

BATESON, T.F. \& SCHWARTZ, J. (2004): "Who is sensitive to the Effects of Particulate Air Pollution on Mortality? A case-crossover analysis of the effect modifiers”, Epidemiology, 15, pp. 143-149.

BERMÚDEZ, M. (2009): “Programa Control de la Tuberculosis”, Epidemióloga, Departamento de Salud, San Juan, Puerto Rico.

BERTOLLO, P. (1998): Assessing ecosystem health in governed landscapes: a framework for developing core indicators. Ecosystem Health 4(1):33-51.

BOFFETTA, P. \& NYBERG, F. (2003): “Contribution to environmental factors to cancer risk”, British Medical Bulletin, 68, pp. 71-94.

BROWN J., \& DAMERY, S. (2002). Managing flood risk in the UK: towards an integration of social and technical perspectives. Transactions of the Institute of British Geographers, 27(4), 412-426. Retrieved from Academic Search Complete database.

BUZAI G., (2006): Análisis Socio espacial con Sistemas de Información Geográfica, Lugar Editorial, Buenos Aires..

Caribbean: what we know and don’t know”, Environmental Geochemistry and Health, 30, pp. 339-343.

Publicado en formato digital: Dr. José Seguinot Barbosa. GEOGRAFÍA MÉDICA Y DE LA SALUD: CONCEPTOS, PARADIGMAS Y VISIONES EN EL CONTEXTO DEL CAMBIO CLIMÁTICO. Revista Geográfica Digital. IGUNNE. Facultad de Humanidades. UNNE. Año 9. № 17. Enero - Junio 2012. ISSN 1668-5180 Resistencia, Chaco. En: http://hum.unne.edu.ar/revistas/geoweb/default.htm 
Revista Geográfica Digital. IGUNNE. Facultad de Humanidades. UNNE. Año 9. № 17. Enero - Junio 2012. ISSN 1668-5180 Resistencia, Chaco

CENTER FOR DISEASE CONTROL AND PREVENTION. "Entomology and Ecology”, Dengue Homepage. Recuperado el 13 de noviembre de 2009 de:

http://www.cdc.gov/dengue/entomologyEcology/index.html

CENTER FOR DISEASE CONTROL AND PREVENTION. “Mosquito Life Cycle, Dengue”, Dengue Homepage. Recuperado el 13 de noviembre de 2009) de:

http://www.cdc.gov/dengue/entomologyEcology/m_lifecycle.html

CENTRO PARA EL CONTROL Y PREVENCIÓN DE ENFERMEDADES. (2009): “Preguntas frecuentes información básica sobre diabetes”. Recuperado el 15 de noviembre de 2009 de: http://www.cdc.gov/diabetes?spanish/faqs.htm.

CENTRO PARA EL MANEJO DE DATOS DE DIABETES. (2002): “Boletín informativo del Centro del Manejo de Datos de Diabetes”. Recuperado el 15 de noviembre de 2009 de: http://www.rcm.upr.edu/PublicHealth/diabetes/Bol- Inf_2002_1.pdf.

CENTROS PARA EL CONTROL Y PREVENCIÓN DE ENFERMEDADES. (2009): “Cáncer de Piel”. Recuperado el 25 de octubre de 2009 de http://www.cdc.gov/spanish/cancer/skin/

CHAN, N. Y. (1999): “An integrated assessment framework for climate change and infectious diseases”, Environmental Health Perspectives, 107, pp. 329.

COMARAZAMY, D.E. et al. (circa 2005): “A validation study of the urban heat island in the tropical coastal city of San Juan, Puerto Rico”, NASA Global Hydrology and Climate Center (NGHCC), Huntsville, AL.

COSTANZA, R. (1992): Toward an operational definition of ecosystem health. Pages 239-256 in R. Costanza, B. G. Norton, and B. D. Haskell, editors. Ecosystem health: new goals for environmental management. Island Press, Washington, D.C., USA.

DEPARTAMENTO DE SALUD DE PUERTO RICO. (2000): “Eventos Vitales 2000”. Recuperado el 13 de octubre de 2009 de: www.salud.gov.pr/estadisticas.

DEPARTAMENTO DE SALUD DE PUERTO RICO. (2004): "Informe de Estadísticas Vitales 2004”. www.salud.gov.pr/estadisticas.

DEPARTAMENTO DE SALUD DE PUERTO RICO. (2008): “Epidemiología de la Tuberculosis en Puerto Rico”, Programa Control de Tuberculosis, Departamento de Salud de Puerto Rico (Epidemiology of Tuberculosis in Puerto Rico, 2004-2008).

DEPARTAMENTO DE SALUD DE PUERTO RICO. “Datos de Asma”. Recuperado el 15 de noviembre de 2009 de: http://www.salud.gov.pr/Datos/InfoSalud/Asthma/Pages/default.aspx

Publicado en formato digital: Dr. José Seguinot Barbosa. GEOGRAFíA MÉDICA Y DE LA SALUD: CONCEPTOS, PARADIGMAS Y VISIONES EN EL CONTEXTO DEL CAMBIO CLIMÁTICO. Revista Geográfica Digital. IGUNNE. Facultad de Humanidades. UNNE. Año 9. № 17. Enero - Junio 2012. ISSN 1668-5180 Resistencia, Chaco. En: http://hum.unne.edu.ar/revistas/geoweb/default.htm 
Revista Geográfica Digital. IGUNNE. Facultad de Humanidades. UNNE. Año 9. № 17. Enero - Junio 2012. ISSN 1668-5180 Resistencia, Chaco

DEPARTAMENTO DE SALUD DE PUERTO RICO. “Información general de diabetes”. Prevención de Control y Diabetes. Recuperado el 15 de noviembre de 2009 de: http://www.salud.gov.pr/Services/PrevencionControlDiabetes/Pages/InformacionGeneralDeDiab etes.aspx\#queesladiabetes

DEPARTAMENTO DE SALUD, SECRETARIA AUXILIAR DE PLANIFICACIÓN Y DESARROLLO, DIVISIÓN DE ANÁLISIS ESTADÍSTICO. (2005): “Tasas de mortalidad general por regiones de salud, municipio de residencia y causas específicas, Puerto Rico”.

DÍAZ, N. et al. (1990): “Informe de la División de epidemiología del Departamento de salud de Puerto Rico, Programas de Casos de enfermedades transmisibles informados.

DOHERTY, O.M. (2008): "Saharan mineral dust transport into the Caribbean: Observed atmospheric controls and trends”, Journal of Geophysical Research, doi:10.1029/2007JD009171 [Online 2008].

DUGDALE, D. \& VYAS, J. (2008): “Tuberculosis Pulmonar”, Biblioteca Nacional de Medicina de EE. UU. Recuperado el 17 de noviembre de 2009 de: http://www.nlm.nih.gov/medlineplus

FALCONER A \& FOREMAN J. (2002): A System for Survival: GIS and Sustainable Development, ESRI Press, 2002, Redland, California.

FOSCHIATTI, (2002): Vulnerabilidad Global y Pobreza, Serie medio ambiente No50, CEPAL Santiago, pág. 7-10

FRICH, P. (2002): "Global changes in climatic extremes during the 2nd half of the 20th century”, Climate Research, 19, pp. 193-212.

FRUMKIN H. (2005): Environmental Health: From global to local, John Wiey and Sons, San Francisco, USA.

GARRISON, V.H. et al. (2006): "Saharan dust - a carrier of persistent organic pollutants, metals and microbes to the Caribbean?”, Revista de Biología Tropical, 54, pp. 9-21.

GIANNINI, A. (2000): “Interannual variability of Caribbean rainfall, ENSO and the Atlantic Ocean”, Journal of Climate, 13, pp. 297-311.

Global Climate Change and Children's Health. Pediatrics, 120(5), 1149-1152. doi:10.1542/peds.2007-2645.

GONZÁLEZ, J.E. et al. (2005): “Urban Heat Islands Developing in Coastal Tropical Cities” Eos, Transactions, American Geophysical Union, 86(42), pp. 398-412.

Gordon, B., Mackay, R., \& Rehfuess, E. (2004). Chapter 20: Climate Change. (pp. 46-47). World Health Organization. Retrieved from Academic Search Complete database.

Publicado en formato digital: Dr. José Seguinot Barbosa. GEOGRAFÍA MÉDICA Y DE LA SALUD: CONCEPTOS, PARADIGMAS Y VISIONES EN EL CONTEXTO DEL CAMBIO CLIMÁTICO. Revista Geográfica Digital. IGUNNE. Facultad de Humanidades. UNNE. Año 9. № 17. Enero - Junio 2012. ISSN 1668-5180 Resistencia, Chaco. En: http://hum.unne.edu.ar/revistas/geoweb/default.htm 
Revista Geográfica Digital. IGUNNE. Facultad de Humanidades. UNNE. Año 9. № 17. Enero - Junio 2012. ISSN 1668-5180 Resistencia, Chaco

GRIFFIN, D.W. (2007): “Atmospheric movement of microorganisms in clouds of desert dust

GROISMAN, P. et al. (1999): "Changes in the probabilities of heavy precipitation: Important indicators of climatic change”. Climate Change, 42, pp. 243- 283.

GULATI, S. \& MAHESHWARI, A. (2007): “Atypical manifestations of dengue”, Tropical Medicine \& International Health, 12(9), pp. 1087-1095.

HAINES, A. (2008): “Climate Change and Health, Strengthening the Evidence Base for Policy”, American Journal of Preventive Medicine, 35(5), pp. 411-413.

HILL, D. (1993): “Changes in sun-related attitudes and behaviors, and reduced sunburn prevalence in a population at high risk of melanoma”, European Journal of Cancer Prevention, 2, pp. 447-456. http://www.nlm.nih.gov/medlineplus/spanish/ency/article/001442.htm

HÜBLER, M. et al. (2008): "Costs of climate change, the effects of rising temperatures on health and productivity in Germany”, Ecological Economics 68, pp. 381-393.

INTERGOVERNMENTAL PANEL ON CLIMATE CHANGE. (2007): "Climate Change: Impacts, Adaptation and Vulnerability". Recuperado el 20 de noviembre de 2009 de: http://www.ipcc.ch/pdf/assessment-report/ar4/wg2/ar4-wg2-chapter1.pdf.

IÑIGUEZ L. (2003): Geografía de la Salud, Revista Cubana de Salud Pública; 29(4): 293-294.

JENSEN A. H., (1980): Geography History and Concepts, Barnes \& noble Books, New Jersey.

KILBOURNE, E.M. (1997): “Heat waves and hot environments”. In: Noji EK, ed. The public health consequences of disasters. New York, New York: Oxford University Press, pp. 245-69.

KOHN R., LEVAY, GARCIA, MACHUCA \& TAMASHIRO, (2005): Prevalence, risk factors and aging vulnerability for psychopathology following a natural disaster in a developing country. International Journal of Geriatric Psychiatry, 20(9), 835-841. doi:10.1002/gps.1369.

KOVATS, R.S. et al. (2003): “El Nino and health”, Lancet, 362, pp. 1481-9.

KURYLOWICZ, A. et al. (2007): “The influence of vitamin D deficiency on cancers and autoimmune diseases development”, Endokrinologia Poslka, 58(2), pp. 140-152.

LANG L. (2001), GIS for Health Organizations, ESRI Press, Redland California.

LUBER, G. \& MCGEEHIN, M. (2008): “Climate Change and Extreme Heat Events”, American Journal of Preventive Medicine, 35(5), pp. 429-435.

LUGO-AMADOR, N.M. et al. (2004): “Heat-related illness”, Emergency Medicine Clinics of North America, 22, pp. 315-27.

Publicado en formato digital: Dr. José Seguinot Barbosa. GEOGRAFÍA MÉDICA Y DE LA SALUD: CONCEPTOS, PARADIGMAS Y VISIONES EN EL CONTEXTO DEL CAMBIO CLIMÁTICO. Revista Geográfica Digital. IGUNNE. Facultad de Humanidades. UNNE. Año 9. No 17. Enero - Junio 2012. ISSN 1668-5180 Resistencia, Chaco. En: http://hum.unne.edu.ar/revistas/geoweb/default.htm 
Revista Geográfica Digital. IGUNNE. Facultad de Humanidades. UNNE. Año 9. № 17. Enero - Junio 2012. ISSN 1668-5180 Resistencia, Chaco

MAHESWARAN R. (2004): GIS in Public Health Practice, CRC Press, USA.

MARTEN, W. J. M. (1998): "Health impacts of climate change and ozone depletion: An ecoepidemiologic modeling approach”, Environmental Health Perspective, 16(1), pp. 241-251.

MASSANET J.C., (1999): LA Geografía Médica de la Ciudad: Un Estudio Comparativo de las Condiciones de Salud y Riesgo Ambiental del Viejo San Juan y la Habana Vieja, Escuela Graduada de Salud Pública, Tesis, Recinto de Ciencias Médicas, Universidad de Puerto Rico.

MEADE M. (2000), Medical Geography, Guilford Press, New York.

MEDLINE PLUS. “Diabetes Tipo 2”. Biblioteca Nacional de Medicina en EEUU y los Institutos Nacionales de Salud. Recuperado el 15 de noviembre de 2009 de:

http://www.nlm.nih.gov/medlineplus/spanish/ency/article/000313.htm

MORENO, A. y otros (2005): Sistemas y análisis de la información geográfica. Manual de auto aprendizaje con ArcGIS, Madrid, Editorial Ra-Ma, 2005.

MUÑOZ, C. et al (2004): "Melanoma in situ in Puerto Rico: Clinical characteristics and detection patterns”, Puerto Rico Health Sciences Journal, 23(3), pp. 179-182.

MUÑOZ T, AGUILAR B. \& SISK D, (2007), Linking Ecosystem Health Indicators and Collaborative Management: a Systematic Framework to Evaluate Ecological and Social Outcomes, Ecology and Society 12(2): 6, http://www.ecologyandsociety.org/vol12/iss2/art6/

NATIONAL ASTHMA EDUCATION AND PREVENTION PROGRAM EXPERT PANEL REPORT 3. GUIDELINES FOR THE DIAGNOSIS AND MANAGEMENT OF ASTHMA. (2007):

NIEVES-RAMÍREZ, G. (viernes, 10 de enero de 2003): “Estudio sobre el calor”. El Nuevo Día. Recuperado el 21 de septiembre de 2009 de: http://www.endi.com.

ORGANIZACIÓN DE LAS NACIONES UNIDAS. (1992): “Convención Marco de las Naciones Unidas sobre el Cambio Climático”. Recuperado el 15 de noviembre de 2009 de: http://unfccc.int/resource/docs/convkp/convsp.pdf.

ORGANIZACIÓN MUNDIAL DE LA SALUD. (16 de enero de 2008): “Cambio climático y salud". Recuperado el 15 de noviembre de 2009 de:

http://apps.who.int/gb/ebwha/pdf_files/EB122/B122_4-sp.pdf.

Publicado en formato digital: Dr. José Seguinot Barbosa. GEOGRAFíA MÉDICA Y DE LA SALUD: CONCEPTOS, PARADIGMAS Y VISIONES EN EL CONTEXTO DEL CAMBIO CLIMÁTICO. Revista Geográfica Digital. IGUNNE. Facultad de Humanidades. UNNE. Año 9. № 17. Enero - Junio 2012. ISSN 1668-5180 Resistencia, Chaco. En: http://hum.unne.edu.ar/revistas/geoweb/default.htm 
Revista Geográfica Digital. IGUNNE. Facultad de Humanidades. UNNE. Año 9. № 17. Enero - Junio 2012. ISSN 1668-5180 Resistencia, Chaco

ORGANIZACIÓN MUNDIAL DE LA SALUD. “Climate change and human health”. Programas y Proyectos. Recuperado el 15 de noviembre de 2009 de: http://www.who.int/globalchange/climate/es/index.html

PÉREZ-GUERRA, C.L. (2009): “Community beliefs and practices about dengue in Puerto Rico”, Revista Panamericana de Salud Pública, 25(3), pp. 218-26.

PROSPERO, J. M. (1999): "Long-range transport of mineral dust in the global atmosphere: impact of African dust on the environment of the southeastern United States”, Proceedings of the National Academy of Science, USA, 96, pp. 3396-3403.

RAPPORT, D. J. (1998): Defining ecosystem health. Pages 18-33 in D. Rapport, R. Costanza, P. Epstein, C. Gaudet, and R. Levins, editors. Ecosystem health. Blackwell, Malden, Massachusetts, USA.

REGISTRO DE CÁNCER DE PUERTO RICO, Departamento de Salud de Puerto Rico. (2009): “Datos de cáncer: Incidencia”. Recuperado el 1 de noviembre de 2009 de http://www.salud.gov.pr/RCancer/Reports/Incidence/Pages/Age\%20Adjusted\%20Incidence\%20 Rates\%20by\%20Sex\%20For\%20Selected\%20Site,\%20All\%20Ages.aspx

RULlÁN, J. (2004): “Ojo a la Tuberculosis”, Departamento de la Salud de Puerto Rico. Recuperado el 17 de noviembre de 2009 de: www.salud.gov.pr.

SCHWARTZ, S. M. et al (1987): "Seasonal variation in the incidence of Cutaneous malignant melanoma: an analysis of the body site and histologic type”, American Journal of Epidemiology, 126(1), pp. 104-111.

SEGUINOT J. (2005): GeoCaribe: Medio ambiente Cultura y Salud en el Caribe Contemporáneo, Ed. Geo, San Juan, Puerto Rico.

SEGUINOT J (2001): Geonatura: Aplicaciones de los Sistemas de Información Geográfica en las Ciencias Ambientales y de la Salud, Publicaciones CD, San Juan, Puerto Rico.

SINC. (17 de febrero de 2009): "El clima local influye en la transmisión del dengue”, Servicio de información y noticias científicas, Biomedicina y salud. Recuperado el 13 de noviembre de 2009 de: http://www.plataformasinc.es/index.php/esl/Noticias/El-clima-local-influye-en-la$\underline{\text { transmision-del-dengue }}$

TAMBURLINI, G. et al. (2002): "Children's health and environment: A review of evidence”, Environmental Issue Report, No29 EEA-WHO. Copenhagen.

Publicado en formato digital: Dr. José Seguinot Barbosa. GEOGRAFÍA MÉDICA Y DE LA SALUD: CONCEPTOS, PARADIGMAS Y VISIONES EN EL CONTEXTO DEL CAMBIO CLIMÁTICO. Revista Geográfica Digital. IGUNNE. Facultad de Humanidades. UNNE. Año 9. No 17. Enero - Junio 2012. ISSN 1668-5180 Resistencia, Chaco. En: http://hum.unne.edu.ar/revistas/geoweb/default.htm 
U.S. DEPARTMENT OF HEALTH \& HUMAN SERVICES. (30 de abril de 2009): U.S. Food and Drug Administration. Recuperado el 15 de noviembre de 2009 de:

http://www.fda.gov/ForConsumers/ByAudience/ForWomen/FreePublications/ucm126242.htm

UNITED NATIONS POPULATION FUND. (1999): The state of world population 1999, pp. 76, New York. Recuperado el 21 de septiembre de 2009 de:

http://www.unfpa.org/swp/1999/index.htm.

VALENTIN, S. M. (2007): “Epidemiology of Melamona in Puerto Rico, 1987-2002”, Puerto Rico Health Sciences Journal, 26(4), pp. 343-348.

VARGAS-SAAVEDRA, M. (viernes, 10 de enero de 2003): "Discuten estudios sobre cambios del clima en el Caribe”, Primera Hora. Recuperado el 21 de septiembre de 2009 de: http://www.primerahora.com.

VELÁZQUEZ, A. et al. (2005): “Urban heat island effect analysis in San Juan, Puerto Rico”, Atmospheric Environment, in press.

WORLD HEALTH ORGANIZATION. (2009): "How common is skin cancer?” Recuperado el 28 de octubre de 2009 de http://www.who.int/uv/faq/skincancer/en/index1.html

YAHANA S., AHMAD N., \& ABDALLA, R. (2010): Multicriteria Analysis for Flood Vulnerable Areas in Hadejia-Jama'are River Basin, Nigeria. European Journal of Scientific Research, 42(1), 71-83. Retrieved from Academic Search Complete database.

YOUNGER, M. et al. (2008): “The Built Environment, Climate Change, and Health, Opportunities for Co-Benefits”, American Journal of Preventive Medicine, 35(5), pp. 517-526.

Zahran, S., Brody, S., Peacock, W., Vedlitz, A., \& Grover, H. (2008). Social vulnerability and the natural and built environment: a model of flood casualties in Texas. Disasters, 32(4), 537560. doi:10.1111/j.1467-7717.2008.01054.x.

\footnotetext{
Publicado en formato digital: Dr. José Seguinot Barbosa. GEOGRAFÍA MÉDICA Y DE LA SALUD: CONCEPTOS, PARADIGMAS Y VISIONES EN EL CONTEXTO DEL CAMBIO CLIMÁTICO. Revista Geográfica Digital. IGUNNE. Facultad de Humanidades. UNNE. Año 9. No 17. Enero - Junio 2012. ISSN 1668-5180 Resistencia, Chaco. En: http://hum.unne.edu.ar/revistas/geoweb/default.htm
} 